\title{
Formação de leitores na sociedade da informação: o que dizem as pesquisas recentes?
}

\section{Training of readers in the information society: what do recent researchers say?}

https://doi.org/10.34112/2317-0972a2019v37n76p41-58

\section{Márcia Regina Rodrigues Ferreira ${ }^{1}$ \\ Patrícia Veronesi Batista ${ }^{2}$}

RESUMO: Considerando que vivemos em uma sociedade marcada pelo excesso de informação e ausência de experiências consistentes de leitura, este trabalho analisa pesquisas recentes que relacionam os conceitos de formação de leitores ao contexto da sociedade da informação, a fim de destacar ações que podem contribuir para a formação de leitores competentes. $\mathrm{O}$ aporte teórico é marcado, principalmente, por contribuições de Walter Benjamin e Jorge Larrosa Bondía. A pesquisa compreende um estudo bibliográfico, de caráter exploratório e descritivo, que analisa os dados qualitativamente. Destaca-se a importância de buscar meios para assumir os desafios que a sociedade da informação apresenta e transformá-los em oportunidades de ressignificação do papel de importância da escola, dos professores e bibliotecários para o desenvolvimento da leitura, escrita e competência informacional.

Palavras-ChAVE: Formação de leitores; competência informacional; Sociedade da Informação.

ABSTRACT: Considering that we live in a society marked by excessive information and absence of consistent reading experiences, this paper analyzes recent research that relates the concepts of reader formation to the context of the information society in order to highlight

1. Secretaria Municipal de Educação de Santa Teresa, Santa Teresa, ES, Brasil.

2. Universidade Federal do Espírito Santo, Vitória, ES, Brasil. 
actions that can contribute to the formation of competent readers. The theoretical contribution is mainly marked by contributions of Walter Benjamin and Jorge Larrosa Bondía. The research comprises a bibliographic study, exploratory and descriptive, that analyzes the data qualitatively. It was highlighted the importance of finding means to assume the challenges that the information society presents and turn them into opportunities of re-signification of the importance role of the school, teachers and librarians for the development of reading, writing and informational competence.

KEYWORDS: Readers formation; informational competence; Information Society.

\section{INTRODUÇãO}

A sociedade da informação, que tem início no final do século XX e é fortemente relacionada ao conceito de globalização, encontra-se em contínuo processo de formação e ampliação. Como bem sugere a expressão, essa sociedade é norteada pela informação e pelas tecnologias que propiciam sua disseminação. Lecardelli e Prado (2006, p. 27) apontam que "[...] o uso e domínio da informação em qualquer formato que se apresenta, tornou-se fundamental na Sociedade da Informação e do Conhecimento".

Essa nova era vem acompanhada de implicações para a educação, visto que exige o desenvolvimento e constante renovação de habilidades, conhecimentos e atitudes para que estejamos aptos a lidar com as inúmeras mudanças. Acabamos nos tornando seres reativos, envoltos em um universo de informações que surgem a todo momento; chegamos a perder de vista, e em muitos casos nem nos apropriamos de fato, de um espaço de liberdade, reflexão e autonomia.

$O$ excesso de informação e a rapidez com que acontecimentos, posicionamentos e opiniões são veiculados na atual sociedade da informação exigem leituras igualmente velozes, instantâneas e, consequentemente, frágeis, rasas, superficiais, resultando na ausência de experiências de leitura, de escuta, de contemplação, de sensibilidade e de consistência na formação leitora. Essa concepção vai ao encontro das discussões de Benjamin (1987), que será importante aporte teórico.

Considerando que vivemos em uma sociedade marcada pelo excesso de informação e ausência de experiências consistentes de leitura, problematiza-se a seguinte questão: como as recentes pesquisas relacionam os conceitos de formação de leitores e sociedade da informação com o propósito de refletir sobre as condições para formação de leitores competentes? 
Tal questionamento se mostra relevante do ponto de vista social e intelectual, tendo em vista os desafios que a sociedade da informação nos coloca, no que tange à educação e, mais especificamente, à formação de leitores.

Sabe-se que são pontuais, descontínuas e inconsistentes as ações e projetos visando a formação de leitores no Brasil, o que impede o acesso efetivo de milhares de pessoas ao mundo letrado e acarreta outras exclusões sociais.

Em contrapartida, Soares (2000), em Letrar é mais que alfabetizar, afirma que as sociedades atuais se mostram cada vez mais centradas na escrita, intensificando-se as demandas por práticas de leitura e escrita, especialmente em meio aos variados recursos tecnológicos e suportes informacionais.

Vê-se que refletir sobre a formação de leitores na sociedade da informação requer o desafio de repensar práticas e reconhecer limitações no modo como vivemos e nos relacionamos na contemporaneidade; principalmente, exige reconhecer como tais práticas e realidades comprometem a qualidade de nossa formação leitora.

Acredita-se, ainda, que são escassos os estudos que relacionam a formação de leitores ao contexto da sociedade da informação. Nesse caso, sistematizar as pesquisas recentes vai permitir um diagnóstico significativo das discussões e teorias, possibilitando dar continuidade aos estudos e ampliar conhecimentos.

Diante do exposto, tem-se como objetivo geral: analisar pesquisas recentes sobre formação de leitores na sociedade da informação, realizadas no período de 2000 a 2018, e destacar ações que podem contribuir para a formação de leitores competentes. E, como objetivos específicos: discutir conceitos imbricados à compreensão da leitura na sociedade contemporânea, sistematizar as reflexões de diferentes autores sobre o tema investigado e identificar ações que podem contribuir para a formação de leitores competentes na sociedade da informação.

\section{EXPERIÊNCIA E INFORMAÇÃO: QUESTÕES TEÓRICAS}

\section{DECLÍNIO DA EXPERIÊNCIA E ASCENSÃO DA INFORMAÇÃO}

Benjamin (1987, p. 198) analisa o que pode ser compreendido como a origem do processo que vem destituindo a humanidade de experiências coletivas, levando a vivências de isolamento e não de partilha. Os reflexos do pós-guerra, no modo como a humanidade passou a se relacionar, nos privou da capacidade de "intercambiar experiências" e tal processo continuará seu curso, podendo resultar até 
no desaparecimento de construções coletivas plenas de significação. Dessa forma, o desaparecimento de experiências é apresentado como fenômeno motivador do processo de declínio da narrativa, uma vez que rompe com as construções coletivas de sentidos que são partilhadas por meio das relações interpessoais.

O surgimento do romance é visto como primeiro indício da morte da narrativa; uma vez vinculado ao livro, ele se torna uma invenção da imprensa e tem origem no indivíduo, não procedendo mais da tradição oral que se fundamenta nas experiências coletivas.

Com o desenvolvimento da imprensa, acaba por surgir outra modalidade de comunicação humana, igualmente avessa à narrativa, porém, mais ameaçadora, capaz de colocar em risco o próprio romance: a informação.

Atualmente, vive-se a era da informação; as relações humanas se tornaram mais complexas e já não se pode contar, ao menos não como antes, com as experiências socialmente construídas para dar conta das certezas e incompletudes que nos constituem. Vivemos agora sob influência da informação.

Deve-se considerar, contudo, o que Ferreira (2015) destaca, em pesquisa que reflete a respeito da importância da memória e das experiências socialmente construídas pelos sujeitos, sobre a capacidade que a narrativa tem de perdurar no tempo, conservando suas forças, podendo, mesmo sob efeito do tempo, repercutir em desdobramentos. Potencial que a informação, por sua natureza fugaz, não possui.

Larrosa Bondía (2002, p. 21) nos convida a "pensar a educação a partir do par experiência/sentido". Ele entende que "pensar não é somente 'raciocinar' ou 'calcular' ou 'argumentar", mas "sobretudo dar sentido ao que somos e ao que nos acontece", estando o sentido diretamente relacionado às palavras.

Ao tratar da importância das palavras, Larrosa Bondía (2002, p. 21) apresenta o conceito de experiência como "o que nos passa, o que nos acontece, o que nos toca", e cita Benjamin, que "em um texto célebre, já observava a pobreza de experiências que caracteriza o nosso mundo. Nunca se passaram tantas coisas, mas a experiência é cada vez mais rara”.

Problematiza-se a ênfase dada à informação na sociedade contemporânea e o excesso de informação, que não favorece a experiência. A informação "é quase o contrário da experiência, quase uma antiexperiência” (LARROSA BONDÍA, 2002, p. 21):

seguramente todos já ouvimos que vivemos numa 'sociedade de informação'. E já nos demos conta de que esta estranha expressão funciona às vezes como sinônima de 
'sociedade do conhecimento' ou até mesmo de 'sociedade de aprendizagem. Não deixa de ser curiosa a troca, a intercambialidade entre os termos 'informação', 'conhecimento' e 'aprendizagem'. Como se o conhecimento se desse sob a forma de informação, e como se aprender não fosse outra coisa que não adquirir e processar informação (LARROSA BONDÍA, 2002, p. 22).

Além do excesso de informação, o autor supracitado elenca ainda o excesso de opinião, a falta de tempo e o excesso de trabalho como fatores que contribuem para que a experiência se mostre cada vez mais rara. E destaca:

A experiência, a possibilidade de que algo nos aconteça ou nos toque, requer um gesto de interrupção, um gesto que é quase impossível nos tempos que correm: requer parar para pensar, parar para olhar, parar para escutar, pensar mais devagar, olhar mais devagar, e escutar mais devagar; parar para sentir, sentir mais devagar, demorar-se nos detalhes, suspender a opinião, suspender o juízo, suspender a vontade, suspender o automatismo da ação, cultivar a atenção e a delicadeza, abrir os olhos e os ouvidos, falar sobre o que nos acontece, aprender a lentidão, escutar aos outros, cultivar a arte do encontro, calar muito, ter paciência e dar-se tempo e espaço (LARROSA BONDÍA, 2002, p. 24).

A experiência seria então "um encontro ou uma relação com algo que se experimenta, que se prova"; seria "aquilo que [...] nos toca, ou que nos acontece, e ao nos passar nos forma e nos transforma." Larrosa Bondía entende que "o saber da experiência é um saber particular, subjetivo, relativo, contingente, pessoal” (2002, p. 25-26).

Diante do exposto, nos perguntamos se há espaço para a experiência em meio à sociedade da informação. Afinal, que sociedade é essa? Quais são suas principais características? E quais os desafios para a formação de leitores competentes?

\section{SOCIEDADE DA INFORMAÇÃo}

A sociedade da informação tem início no final do século XX, é fortemente relacionada ao conceito de globalização, encontra-se em contínuo processo de desenvolvimento, interferindo em aspectos econômicos, tecnológicos, socioculturais e educacionais, transformando significativamente o modo como as pessoas vivem e se relacionam na atualidade. 
Teresa Silveira (2016, p. 3) conceitua sociedade da informação, afirmando que a expressão é "atribuída a um novo modelo, que assenta num modo de desenvolvimento social e econômico onde a informação é um meio de criação de conhecimento". Referindo-se ao novo paradigma social, acrescenta, ainda, que será responsável por transformações nos sistemas econômicos, nas noções de ética, nas relações sociais e até no desenvolvimento cognitivo de suas gerações.

Assmann (2000, p. 8-9) caracteriza a sociedade da informação pelo amplo uso de "tecnologias de armazenamento e transmissão de dados e informação de baixo custo". Ressalta a multiplicidade de significados que o conceito informação permite apontar e reconhece que para transformar-se em conhecimento necessita passar por um "processo relacional humano, e não mera operação tecnológica". Dessa forma, a simples disponibilização de informações "não basta para caracterizar uma Sociedade da Informação. $\mathrm{O}$ mais importante é o desencadeamento de um vasto e continuado processo de aprendizagem".

Mata (2009, p. 70) compreende a sociedade da informação como uma economia nova, baseada na informação e em tecnologias, que por sua vez acarreta dilemas para a educação, tornando-se necessário "acompanhar as tendências atuais, colocando o aprendiz no centro do processo, preparando-o para aprender a aprender e para ter condições de viver no século XXI".

A importância de "aprender a aprender" se torna ainda mais urgente ao considerar que a informação pode tanto informar como desinformar, a depender de como é manuseada, sendo o desenvolvimento da competência informacional um processo de preparação do indivíduo para uma postura responsável e autônoma, que "pode guiar ou mostrar uma nova perspectiva capaz de influenciar fortemente suas vidas e seu modo de agir” (MATA, 2009, p. 72).

O senso crítico é apontado como preponderante para avaliação da informação, em termos de qualidade, confiabilidade e pertinência do conteúdo perante as necessidades informacionais; logo, deve ser trabalhado em conjunto com o desenvolvimento da competência informacional, estando esta última mais diretamente relacionada à capacidade de aprender a lidar com a informação nos variados suportes, canais e fontes que surgem a todo momento.

A competência informacional preocupa-se com a formação do indivíduo, colocando-o como o cerne do processo, e também com sua transformação através da informação. Procura habilitá-lo a usar a informação, fazendo-o tomar conhecimento dos 
suportes em que esta se encontra disponível para poder localizá-la, selecioná-la e por fim usá-la. Desse modo, possibilita-lhe conquistar a sua autonomia, guiando-o para o aprender a aprender (MATA, 2009, p. 72-73).

Silva (2009, p. 176), corroborando com o que foi apresentado, acrescenta que a sociedade da informação surge acompanhada de uma "necessidade de competência crítica para selecionar insumos", que por sua vez está diretamente atrelada à proficiência leitora.

Vê-se que a sociedade da informação requer mais do que estrutura tecnológica de comunicação e informação para garantir seu real desenvolvimento; requer uma série de competências ${ }^{3}$ que oferecem aos sujeitos condições para transformar informação em conhecimento.

\section{Abordagem METOdológica}

O presente artigo é resultado de um estudo bibliográfico, de caráter exploratório e descritivo, que avaliou os dados qualitativamente, com o propósito de analisar as pesquisas recentes (publicadas no Portal de Periódicos da Capes, no período compreendido entre os anos 2000 e 2018), que nos permitem refletir sobre a formação de leitores no contexto da sociedade da informação, assim como identificar autores que abordam o tema, suas reflexões e ações que podem contribuir para formação de leitores competentes.

Inicialmente, foram definidos os conceitos fundamentais para montar a estratégia de busca para o levantamento de fontes, resultando em: "formação de leitores"

3. O conceito de competência mencionado não está comprometido com os sentidos tradicionalmente assumidos nos documentos oficiais nacionais e/ou em políticas públicas da área da educação, no que diz respeito a sua vinculação às características individuais dos sujeitos, quanto a sua capacidade de realizar atividades práticas, de integrar-se ao mercado de trabalho, a serviço de concepções utilitárias e alienantes de trabalho. Busca-se trabalhar uma concepção holística do ser humano, as dimensões sociais dos processos de produção de conhecimentos, do saber como construção histórico-social que é externo ao ser humano, o qual deve ser apropriado por meio da educação e de processos sociais, não individuais. O referido termo remete ao contexto dos saberes da Biblioteconomia, no que diz respeito à information literacy (ou competência informacional), expressão surgida nos Estados Unidos (nos anos 1970) e que passou a ser utilizada no Brasil (nos anos 2000), com base na tradução "alfabetização informacional", encontrando-se ainda em construção na área biblioteconômica. Sabe-se do potencial transdisciplinar do termo e, sem desconsiderar a pertinência de problematizá-lo, não nos dedicaremos, nesta oportunidade, a estudar pontos de convergência e divergência entre os contextos de uso. 
AND "sociedade da informação". Diante da baixa recuperação de documentos, a estratégia foi reformulada para Formação de Leitores AND Sociedade da Informação, retirando-se as aspas das expressões, o que permitiu maior recuperação, visto que o operador booleano utilizado possibilitou a interseção das palavras e não mais das expressões, cabendo a análises individuais a garantia da precisão dos resultados.

Foram selecionados artigos nacionais que estabelecem relação entre os conceitos de formação de leitores e sociedade da informação, mesmo quando apresentados por expressões sinônimas, como, por exemplo, "desenvolvimento da leitura" ou "competência leitora" e "sociedade contemporânea" ou "era da informação". Em seguida, foram descartadas fontes que tratavam especificamente sobre letramento digital ou competência leitora, tendo em vista que se propõe abordar uma mescla dessas competências.

Por não haver a pretensão de esgotar o assunto em pesquisa, optou-se por trabalhar mais atentamente um quantitativo de dez artigos, tendo em vista os que atendiam à discussão proposta neste trabalho.

As discussões fundamentam uma posterior sistematização, organizada por categorias de assuntos que se mostraram importantes para pensar a formação de leitores na sociedade da informação. São elas: reinvenção das escolas, reinvenção dos profissionais da educação, reinvenção das práticas de leitura e leitores competentes.

FORMAÇÃO DE LEITORES NA SOCIEDADE DA INFORMAÇÃO:

MAPEAMENTO DE PESQUISAS RECENTES

O QUE DIZEM AS PESQUISAS

Retomando as reflexões teóricas benjaminianas, Luana Ferraz e Fabiano de Oliveira Moraes (2014) em Narrativa e leitura: da experiência às letras, ilustram reflexões realizadas em contato com a obra $O$ Narrador, reconhecem que os meios de comunicação de massa nos possibilitam acesso à informação como nunca antes e que por meio deles nos tornamos "sujeitos obcecados pela informação, pelas novidades que podemos acessar a cada minuto" (FERRAZ; MORAES, 2014, p. 293). Contudo, tais informações não repercutem em nós: 
o mérito da novidade é, exatamente, ser 'nova', e, também por isso, as informações que volumosamente nos chegam não têm tempo de deixar rastro. Sabemos muitas coisas, mas nada efetivamente nos toca, nada nos acontece (FERRAZ; MORAIS, 2014, p. 293).

As reflexões levantadas apontam que o simples acesso à informação não tem garantido compreensões significativas do que nos acontece, não tem proporcionado a leitura de mundo que conduz à emancipação dos sujeitos, e assim, mostra-se urgente pensar as formas de leitura e sua mediação, visando dotar os leitores da capacidade de aprofundar concepções.

Cassia Cordeiro Furtado e Lidia Oliveira (2010, p. 16), em A Biblioteca Escolar na Formação de Comunidades de leitores-autores via web, descrevem a leitura como "um processo de atribuição de significados e sentidos, incorporados na prática humana, com base na família e sendo fortemente influenciada pelas instituições e organizações [...], como escola, classe e grupo social, formação profissional, etc.." Logo, a leitura representa uma prática social, que resulta em socialização, e com o surgimento da sociedade da informação, novas tecnologias de comunicação e informação foram incorporadas ao convívio humano, devendo ser exploradas para aproximar a vida escolar da vida cotidiana dos alunos. Dessa forma, sugerem oportunidades para valorizar identidade e prática em comunidade.

Rovilson José da Silva (2009), em Leitura, Biblioteca e Política de Formação de leitores no Brasil, afirma ser impossível pensar em um modelo de sociedade em que as relações não sejam mediadas pela leitura. Ele acredita que os textos e o cotidiano se completam, "ampliam a compreensão do indivíduo sobre si próprio e sobre o mundo em que vive" (SILVA, 2009, p. 84).

Aline Cassol Daga (2016), em Ampliação de vivências como o ato de ler na educação escolar em linguagem: uma discussão sobre a intersubjetividade e a formação de leitores, defende que $\mathrm{o}$ ato de ler é uma atividade essencialmente humana, a partir da qual a escola tem papel fundamental.

O ensino-aprendizagem de língua se destaca pela transversalidade de abordagens que possibilita e pela capacidade discursiva que proporciona na formação crítica do estudante, somado ao já mencionado natural potencial comunicativo do ser humano.

É o que Margarida Maria Silva Gomes (2015) reconhece em A transversalidade da língua para uma aprendizagem significativa, ao ressaltar o caráter transversal do aprendizado de língua, tão presente no desenvolvimento humano e fonte de saber em diversas áreas de conhecimento, visto que "aspectos como ler, escrever, argumentar 
e compreender se constituem como competências transversais, cuja importância justifica a sua abordagem de forma inter e transdisciplinar" (GOMES, 2015, p. 3).

Em Letramentos e leitura: reflexões e práticas sobre formação do leitor contemporâneo, Suzana dos Santos Gomes (2017) ressalta a importância que o professor tem nesse processo de ensino-aprendizagem. Dele dependerá a "interação com o texto e com o outro", exigindo que seja também um aprendiz, ou melhor, "somente será capaz de contribuir nesse processo quando tiver oportunidade de se tornar aprendiz ativo e colaborativo" (GOMES, 2017, p. 2), ciente da necessidade da leitura na cultura letrada na qual estamos inseridos.

Pensando especificamente na formação de professores, Fernando Tavares Junior e Roberta Scoton (2014), em Educação, Mídias e Tic: reflexões sobre o papel docente, refletem sobre as potencialidades e os desafios que surgem em consequência da propagação de novas tecnologias da informação e comunicação, e como essas acometem a profissão docente e a escola, tendo em vista as exigências advindas da sociedade da informação e a necessidade de repensar os papéis sociais tradicionalmente desempenhados.

[...] por um lado, discute-se a reconfiguração dos papéis dos sujeitos envolvidos na aprendizagem, a partir da qual o professor passaria a ser um mediador entre os alunos e os conhecimentos em contínua produção. Por outro lado, destaca-se a modificação no acesso às informações e seu volume. A escola e o professor deixariam de ser o centro institucional do saber. O novo elemento emerge da facilidade de acesso às informações e sua multiplicidade, sem questionamento de confiabilidade, fidedignidade ou mesmo veracidade. A quebra de "monopólio" da escola tradicional como lócus privilegiado de acesso ao saber afeta a aprendizagem desses alunos e sua relação com o que se entende como conhecimento necessário à cidadania (TAVARES JUNIOR; SCOTON, 2014, p. 497).

Dos professores (que em geral são "imigrantes digitais") passa-se a exigir competências para lidar com as tecnologias, de forma que acompanhem as inovações e os interesses dos alunos (que são "nativos digitais"), ampliando os conhecimentos para além dos tradicionais suportes, canais e fontes informacionais consultados.

Em termos práticos, a conexão da escola à rede mundial de computadores permite $\mathrm{o}$ desenvolvimento de diferentes atividades: a) busca ágil de informações (pesquisa escolar, visitas a museus e outros lugares, visitas a sites interativos, artes plásticas, música, 
literatura, cursos virtuais); b) interações com pessoas (fóruns e listas de discussão, comunidades virtuais, chats, e-mails); c) entretenimento (jogos simulações). Todos esses recursos encontram-se disponíveis na internet e esta está presente no cotidiano da maioria dos alunos (TAVARES JUNIOR; SCOTON, 2014, p. 503-504).

Observa-se que as informações se sobrepõem aos limites da escola ou do conhecimento que os professores detêm. Da mesma forma, as tecnologias de informação e comunicação proporcionam outras modalidades de socialização; logo, o aprendizado pode se dar em qualquer espaço, sendo este um potencial que os autores destacam na era da informação, e que, uma vez explorado, confere ao professor e à escola status de fundamental participação e importância.

Eliane Fioravante Garcez (2009), em Sociedade da informação e escola: contribuição das bibliotecas escolares, aborda as relações entre sociedade da informação e a escola de educação básica, tendo em vista a necessidade de competências e habilidades específicas para lidar com a informação em um mundo globalizado.

A autora defende a implantação de uma política nacional de informação dedicada a formar pesquisadores, cientistas, professores e cidadãos em geral, a fim de que tenham condições de manipular os diversos conteúdos e suportes informacionais com competência. A discussão conduz a uma reavaliação do papel da escola, da pesquisa, da biblioteca e da internet no espaço escolar. Destaca ainda a necessidade de preparar as pessoas para o acesso qualitativo à informação, o que se mostra mais importante do que a infraestrutura tecnológica em si, afinal, o que realmente importa são as formas de acesso, o que se faz com as informações e como os conhecimentos adquiridos transformam a vida das pessoas. Daí a necessidade de dedicar atenção ao desenvolvimento de competência informacional, entender as contribuições para a educação formal e para a vida na era da informação.

Competência informacional no Brasil: um estudo bibliográfico no período de 2001 $a$ 2005, publicado por Jane Lecardelli e Noêmia Schoffen Prado em 2006, propõe-se a analisar como a competência informacional tem sido abordada no Brasil, os principais autores e temas estudados, fundamentando-se em periódicos e fontes especializadas na área da Ciência da Informação.

A pesquisa retrata que são poucos os estudos nessa área (principalmente no Brasil), que as mudanças tecnológicas exigem transformações nos perfis dos profissionais, tornando necessária a formação continuada e a capacidade de aprender a aprender, tendo a escola papel de fundamental importância para a formação 
emancipadora dos indivíduos, de forma que conduza ao aprendizado contínuo, autônomo e independente.

Um importante aliado nesse processo educacional é destacado: o profissional bibliotecário, ao qual cabe implementar programas de competência informacional que contemplem as necessidades de toda a comunidade escolar.

Em Ler e escrever: (in) formação de leitores na alfabetização de adultos, de Suzyneide Soares Dantas e Mirian de Albuquerque Aquino (2001), as autoras problematizam os conceitos informação, conhecimento e aprendizagem, comumente explorados nas compreensões sobre sociedade da informação, como se natural e obrigatoriamente a informação conduzisse ao conhecimento e este ao aprendizado. E assim se perguntam como é possível "formar cidadãos cibernéticos num país marcado por graves entraves sociais, políticos e econômicos, que apresenta um quadro alarmante de adultos que não dominam as habilidades básicas para atuar de forma efetiva no mundo letrado e informatizado" (DANTAS; AQUINO, 2001, p. 1). As autoras defendem que a escola deve atuar em consonância com os desafios que a sociedade da informação nos impõe, favorecendo acesso às informações que são úteis para a transformação das realidades, ensinando a pensar certo, conforme defendia Paulo Freire (1999, apud DANTAS; AQUINO, 2001, p. 1).

Ao tratar especificamente sobre a (in)formação de leitores, afirmam que tal processo deve se sobrepor à simples decodificação, devendo proporcionar a construção de concepções de mundo, posicionamentos críticos perante as informações e o verdadeiro exercício de cidadania, resultando na capacidade de ouvir, compreender e formar opiniões próprias.

Ao educador cabe o papel de criar condições para que prevaleçam as leituras individuais, construídas por cada aluno, questionando leituras prontas, impostas pela sociedade, apresentando o exercício da leitura como um "ato inteligente, reflexivo e característico do ser humano, um ato de compreensão do mundo, da realidade que nos cerca, em meio à que vivemos" (DANTAS; AQUINO, 2001, p. 6). As pesquisadoras ressaltam que a competência do leitor não diz respeito apenas ao domínio de regras gramaticais, sendo necessário desenvolver outras competências, destacando-se assim a importância da atuação do professor como mediador desse processo de constante aprendizado.

Definido [sic] os objetivos o professor precisa buscar os recursos, as fontes de informação que lhe permitirá trocar significados. E é na procura de informação que entra um outro 
elemento da atividade educativa: a competência do professor de buscar a informação significativa à vida do aluno. Mas a busca de informações é apenas a primeira etapa do objetivo pedagógico. O professor precisa mesmo é permitir que seus alunos tenham acesso à informação e possam apreendê-la de modo significativo. É necessário pois, tratar a informação e organizá-la para apresentação. Daí a urgência do professor saber lidar com práticas informacionais que ultrapassem a mera transferência de informação e que promovam a (in) formação de leitores (DANTAS; AQUINO, 2001, p. 9-10).

Reafirma-se a necessidade de a escola repensar o sentido da leitura e da formação de leitores na contemporaneidade, para que, uma vez formados, os estudantes sejam capazes de realizar leituras críticas, compreender o que ocorre a sua volta e dar continuidade, de forma autônoma e independente, à formação iniciada na escola.

Tem-se então a possibilidade de ver todas as transformações e inovações que a sociedade da informação nos apresenta como oportunidades de ressignificação do papel de importância da escola, dos professores e bibliotecários no desenvolvimento das habilidades de leitura, escrita e competência informacional, requisitos necessários para estar, compreender, participar e transformar o mundo.

\section{- Reinvenção das escolas}

Não negligenciando seu papel de fundamental importância na formação de leitores, a escola deve estar apta a formar sujeitos para acessos de qualidade à informação, com garantia de competência para avaliar credibilidade, validade e confiabilidade das leituras, sabendo se posicionar com segurança e ética perante a profusão de informações que surgem na sociedade da informação.

Essas competências são mais importantes do que a simples presença de inovações tecnológicas nas escolas, pois a mediação, as formas de acesso e de uso dos recursos informacionais são mais decisivas para a melhoria na qualidade de vida das pessoas.

O ensino de língua se mostra estratégico, uma vez que permite abordagens transversais e transdisciplinares por meio da leitura, escrita e discussões que problematizam a vida em comunidade, desenvolvendo o senso crítico para avaliar realidades, necessidades de transformação e participação cidadã.

Reconhece-se assim a importância da escola e seus profissionais estarem preparados para conhecer, avaliar, explorar e apresentar os diversos suportes, canais e fontes informacionais com os quais alunos e comunidade escolar devem ter 
contato para uma atuação/formação de qualidade, vivenciando múltiplas formas de interações socioculturais.

Os desafios de inserir alunos na cultura letrada se somam aos desafios de inseri-los no mundo informacional, e não parece razoável pensar que a escola por si só tenha condições de suprir tais deficiências. Adequado seria essas problemáticas serem pensadas no âmbito das diretrizes curriculares nacionais, na formação e exercício profissional de professores e bibliotecários.

\section{- ReINVENÇÃo dos PROFISSIONAIS DA EDUCAÇÃo}

Diante da profusão de informações com as quais todos têm contato na atualidade, o professor deixou de ser o único detentor do conhecimento e o aprendizado não é mais exclusivo do espaço escolar, o que por sua vez não deve ser visto com desconfiança. Ao docente cabe agora ser o principal mediador entre os alunos e as informações. A relação deve ser de diálogo, partilha e colaboração, alterando significativamente a forma como se dá o aprendizado, sem diminuir a importância da atuação docente.

Permanece a importância do professor na interação com textos, nas práticas de leitura que favorecem reflexão e autonomia, no ensino dos conteúdos, na socialização, na ampliação do repertório literário e cultural dos alunos. Amplia-se, contudo, a participação no trabalho com diversos canais, suportes e fontes informacionais, exigindo novas competências para o aprendizado e o ensino no uso das inovações tecnológicas, devendo o professor ser um exímio leitor, ciente da importância da cultura letrada e informacional na sociedade contemporânea. A formação continuada, a capacidade de seguir aprendendo a aprender se mostram preponderantes para atuar nas demandas que a escola abarca.

Importante aliado nesse processo educacional é o profissional bibliotecário, dotado de conhecimentos para implementar programas de competência informacional que contemplem as necessidades de toda a comunidade escolar.

\section{- REINVENÇÃo dAS PRÁticas de LEITURA}

Deve-se romper com a mera decodificação e com leituras superficiais, que não se comprometem com o aprofundamento das discussões e com a problematização das realidades. 
Atualmente, os meios de comunicação disponibilizam informações a todo momento, porém o simples acesso não tem garantido adequada compreensão sobre o que nos acontece, ficando muito aquém da leitura do mundo que conduz à emancipação dos sujeitos. Torna-se necessário pensar as formas de leitura, sua mediação, a capacidade de ouvir, pensar, compreender e formar opiniões próprias.

A formação de leitores competentes pressupõe o exercício de leituras críticas, que favorecem a compreensão do mundo, das realidades que nos cercam, da contribuição que devemos dar enquanto sujeitos e cidadãos.

As experiências de leitura enquanto práticas sociais devem resultar em socialização, em contato com nossa história e nossa cultura e com as transformações sociais que conduzem a posturas autônomas e independentes, proporcionando condições para dar sequência à formação iniciada na escola.

\section{- ENFIM, LeITORES COMPETENTES}

Os alunos-leitores devem ser preparados para o exercício social da leitura, para experiências práticas que possibilitem aprendizado e troca de conhecimentos entre a comunidade escolar-leitora, apoiados em uma diversidade textual e informacional que exigirá competências para além dos ensinos tradicionalmente conteudistas, nos quais os alunos recebem passivamente as informações. Cabe agora aos leitores a capacidade de desenvolver percepções sobre fontes, canais e suportes informacionais, sobre segurança e ética diante da informação e sobre pertinência, confiabilidade e veracidade do que leem, adquirindo capacidade de escuta, reflexão, diálogo, partilha e colaboração.

O leitor deve se formar interagindo em espaços físicos e/ou virtuais de aprendizagem, como bibliotecas, museus, sites, bases de dados, periódicos, enciclopédias, fóruns de discussão, blogs, jogos, redes sociais, enfim, explorando os recursos disponibilizados em um mundo conectado e globalizado.

Todas as ações se somam à necessidade de acesso aos programas de desenvolvimento de competência informacional durante a passagem pela educação formal, os quais contribuirão significativamente para o acesso qualitativo à informação e para qualidade de vida na era da informação. 


\section{CONSIDERAÇões Finais}

Destacou-se a importância de buscar meios para assumir os desafios que a sociedade da informação apresenta e transformá-los em oportunidades de ressignificação do papel de importância da escola, dos professores e bibliotecários para o desenvolvimento da leitura, escrita e competência informacional.

Reconhece-se o potencial do trabalho partilhado entre professor de língua e bibliotecário para o sucesso da formação de leitores ${ }^{4}$, assim como para efetiva participação na sociedade da informação. Ao bibliotecário cabe dotar a comunidade escolar das competências necessárias para encontrar, analisar, selecionar e fazer uso crítico da informação, e ao professor de língua cabe romper com leituras velozes, superficiais e frágeis, promovendo experiências consistentes de leitura e a conquista da autonomia que possibilita seguir aprendendo a aprender.

A experiência de planejar e desenvolver este trabalho, em consonância com reflexões de Benjamin e Larrosa Bondía, possibilitou pensar a educação como meio que deve conduzir à experiência e à produção de sentido sobre quem somos e o que nos acontece.

\section{REFERÊNCIAS}

ASSMANN, Hugo. A metamorfose do aprender na sociedade da informação. Revista Ci. Inf., Brasília, v. 29, n. 2, p. 7-15, maio/ago. 200o. Disponível em: <http://revista.ibict.br/ciinf/article/ view/882 >. Acesso em: 10 jul. 2018.

BENJAMIN, Walter. Magia e técnica, arte e política: ensaios sobre literatura e história da cultura. 3. ed. São Paulo: Brasiliense, 1987. (Obras escolhidas; v. 1). Disponível em: <https://monoskop. org/images/3/32/Benjamin_Walter_Obras_escolhidas_1.pdf $>$. Acesso em: 20 jul. 2018.

DAGA, Aline Cassol. Ampliação de vivências com o ato de ler na educação escolar em linguagem: uma discussão sobre a intersubjetividade e a formação de leitores. Fórum Linguístico, v. 13, n. 4, p. 1616-1631, 2016. Disponível em: <https://periodicos.ufsc.br/index.php/forum/article/ view/1984-412.2016v13n4p1616>. Acesso em: 20 jul. 2018.

DANTAS, Suzyneide Soares; AQUINO, Mirian de Albuquerque. Ler e escrever: (in) formação de leitores na alfabetização de adultos. Informação \& Sociedade, v. 11, n. 1, 2001. Disponível em: <http://www.brapci.inf.br/_repositorio/2010/11/pdf_f4f29b57bo_oo13683.pdf>. Acesso em: 20 jul. 2018.

4. Evidencia-se o potencial do trabalho partilhado entre professor de língua e bibliotecário. Contudo, não acreditamos que a responsabilidade sobre a formação de leitores seja exclusiva do professor de língua; dessa forma, estendemo-la a todos os demais professores especialistas. 
FERRAZ, Luana; MORAES, Fabiano de Oliveira. Narrativa e leitura: da experiência às letras. Signo, v. 39, n. 66, p. 290-300, 2014. Disponível em: <http://online.unisc.br/seer/index.php/signo/ article/view/4481>. Acesso em: 20 jul. 2018.

FERREIRA, Márcia Regina Rodrigues. História, Memória e Educação das Sensibilidades: o Processo de Patrimonialização da Casa Lambert de Santa Teresa-ES. 2015. Dissertação (Mestrado em Educação). Programa de Pós-Graduação em Educação, Universidade Federal do Espírito Santo, Vitória, 2015. Disponível em: <http://repositorio.ufes.br/bitstream/10/8641/1/tese_9358_ Disserta\%C $3 \% \mathrm{~A}_{7} \mathrm{C}_{3} \% \mathrm{~A}_{3}$ \% $20 \mathrm{M} \% \mathrm{C}_{3} \%$ Arrcia-\%202016.pdf>. Acesso em: 24 jul. 2018.

FURTADO, Cassia Cordeiro; OLIVEIRA, Lidia. A biblioteca escolar na formação de comunidades de leitores-escritores via web. Informação \& Sociedade: Estudos, v. 2, n. 1, 2010. Disponível em: $<$ http://eprints.rclis.org/14573/>. Acesso em: 20 jul. 2018.

GARCEZ, Eliane Fioravante. Sociedade da informação e escola: contribuição das bibliotecas escolares. Revista $A C B$, v. 14, n. 1, p. 9-26, 2009. Disponível em: <https://revista.acbsc.org.br/ $\mathrm{racb} /$ article/view/653>. Acesso em: 20 jul. 2018.

GOMES, Margarida Maria Silva. A transversalidade da língua para uma aprendizagem significativa. Revista de Estudios e Investigación en Psicología y Educación, n. 08, p. 131-135, 2015. Disponível em: <http://revistas.udc.es/index.php/reipe/article/view/1063>. Acesso em: 20 abr. 2018.

GOMES, Suzana dos Santos. Letramentos e leitura: reflexões e práticas sobre formação do leitor contemporâneo. Revista Thema, v. 14, n. 2, p. 1-4, 2017. Disponível em: <http://periodicos.ifsul. edu.br/index.php/thema/article/viewFile/487/ 344>. Acesso em: 20 jul. 2018.

LARROSA BONDÍA, Jorge. Notas sobre a experiência e o saber de experiência. Revista brasileira de educação, n. 19, p. 20-28, 2002. Disponível em: <http://www.scielo.br/pdf/rbedu/n19/n19ao2>. Acesso em: 1 jul. 2018.

LECARDELLI, Jane; PRADO, Noêmia Schoffen. Competência informacional no Brasil: um estudo bibliográfico no período de 2001 a 2005. Revista Brasileira de Biblioteconomia e Documentação: Nova Série, São Paulo, v. 2, n. 2, p. 21-46, dez. 2006. Disponível em: <https://febab.emnuvens. com.br/rbbd/article/view/16>. Acesso em: 20 jul. 2018.

MATA, Marta Leandro da. A competência informacional de graduandos de biblioteconomia da região sudeste: um enfoque nos processos de busca e uso ético da informação. 2009. Dissertação (Mestrado em Ciência da Informação) Universidade Estadual Paulista, São Paulo, 2009. Disponível em: <https://repositorio.unesp.br/handle/11449/93621>. Acesso em: 20 jul. 2018.

SILVA, Rovilson José da. Leitura, biblioteca e política de formação de leitores no Brasil. Brazilian Journal of Information Science, v. 3, n. 2, p. 75-92, 2009. Disponível em: <https://dialnet.unirioja. es/servlet/articulo?codigo $=4363641>$. Acesso em: 20 jul. 2018.

SILVA, Vanessa Lacerda da. Produção do Conhecimento: subsídios para leitura na sociedade da informação - um estudo de caso. Signo, v. 34, n. 57, p. 171-190, 2009. Disponível em: < http://online. unisc.br/seer/index.php/signo/article/view/950>. Acesso em: 20 jul. 2018.

SILVEIRA, Teresa. Born Digital. Bibliotecas para a Vida II: Bibliotecas e leitura. Publicações do Cidehus, 2016. Disponível em: <https://books.openedition.org/cidehus/343>. Acesso em: 20 jul. 2018.

SOARES, Magda. Letrar é mais que alfabetizar. Jornal do Brasil, Rio de Janeiro, 26 nov. 2000. 
TAVARES JUNIOR, Fernando; SCOTON, Roberta. Educação, Mídias e Tic: Reflexões sobre o papel docente. Revista Inter Ação, v. 39, n. 3, p. 493-510, 2014. Disponível em: <https://www. revistas.ufg.br/interacao/article/view/28441>. Acesso em: 20 ju. 2018.

SOBRE AS AUTORAS

Márcia Regina Rodrigues Ferreira é graduada em História (Universidade Federal do Espírito Santo), tem Mestrado em Educação (Universidade Federal do Espírito Santo). É professora coordenadora da formação continuada de profissionais da educação da Secretaria Municipal de Educação de Santa Teresa, Espírito Santo. Nos processos de formação continuada e na área acadêmica tem interesse nos seguintes temas: história vivida e história ensinada, história e memória, educação do campo e memórias, cultura, educação das sensibilidades e patrimônio cultural.

E-mail: marciarrodrigues@live.com.

Patrícia Veronesi Batista é graduada em Língua Portuguesa e Literatura de Língua Portuguesa e é especialista em Oratória, Transversalidade e Didática da Fala para Formação de Professores (Universidade Federal do Espírito Santo). É aluna/pesquisadora do Mestrado em Educação e do bacharelado em Biblioteconomia (Universidade Federal do Espírito Santo). Na área acadêmica tem interesse nos seguintes temas: formação de leitores, políticas públicas de leitura e bibliotecas escolares.

E-mail: veronesi.pb@gmail.com.

Recebido em 26 de dezembro de 2018 e aprovado em 14 de julho de 2019. 